15

\title{
Метод видеогониографии для изучения морфологии боковой поверхности профилированных монокристаллов и прибор для его реализации
}

\author{
(C) С.И. Бахолдин, В.Н. Маслов \\ Физико-технический институт им. А.Ф. Иофрфе РАН, \\ 194021 Санкт-Петербург, Россия \\ ฯ e-mail: maslov812@yandex.ru
}

(Поступило в Редакцию 8 февраля 2017 г.)

Описан метод видеогониографии и прибор для его реализации. Приведены результаты исследования морфологии боковой поверхности профилированных монокристаллических стержней сапфира, выращенных способом Степанова, трех главных кристаллографических ориентаций $c\{0001\}, a\{11 \overline{2} 0\}, m\{10 \overline{1} 0\}$.

DOI: 10.21883/JTF.2018.06.46029.2198

\section{Введение}

В настоящее время монокристаллы являются перспективным функциональным материалом, широко используемым в различных областях науки и техники. Одна из проблем, с которой сталкивается промышленность, это обработка монокристаллов. Такая проблема возникает в связи с высокой или низкой твердостью, хрупкостью или дефицитностью различных материалов. С одной стороны, эту проблему решает предложенный А.В. Степановым способ выращивания непосредственно из расплава монокристаллов с заданным поперечным сечением или профилем (профилированных кристаллов) [1]. Форма профиля в способе Степанова задается при помощи формообразователя, создающего жидкий мениск расплава. С другой стороны, кристаллическим веществам присуща способность самоогранения, являющаяся проявлением анизотропии свободной поверхностной энергии (АСПЭ).

Если формой мениска, задаваемой формообразователем, и тепловыми условиями мы можем управлять, то АСПЭ, как фундаментальное свойство твердого тела, определяется его кристаллической структурой. В связи с этим на боковой поверхности профилированного кристалла проявляются визуально различимые плоские грани и другие морфологические особенности, ранее описанные на качественном уровне [2-6]. Проявление АСПЭ при выращивании кристаллов способом Степанова может играть как положительную роль, например, при выращивании плоских лент с атомно-гладкой поверхностью, так и отрицательную - отклонение от цилиндричности при выращивании кристаллов криволинейного профиля (стержни, трубы). В связи с этим вновь возникает необходимость в дополнительной обработке монокристаллов криволинейного профиля, которая в ряде случаев оказывается процессом невозможным или дорогостоящим. Например, монокристаллы сапфира обладают высокой твердостью и плохо поддаются механической обработке, а монокристаллы фторидов, часто используемых для оптических приборов, обладают весьма совершенной спайностью в связи с чем могут разрушаться при механическом воздействии.

Таким образом, детальное изучение боковой поверхности монокристаллов криволинейного профиля на количественном уровне прежде всего является актуальной практической проблемой. В то же время, АСПЭ как физическое явление в настоящее время изучена явно недостаточно, так как экспериментальное изучение является весьма трудоемким процессом, а расчеты зачастую противоречат результатам эксперимента [7-27]. В связи с этим изучение морфологии боковой поверхности профилированных кристаллов может дать существенный вклад в решение этой фундаментальной научной проблемы.

В настоящей работе объектом изучения стали цилиндрические монокристаллы сапфира, выращенные способом Степанова. Сапфир (лейкосапфир) - современный функциональный материал с уникальными механическими, химическими и оптическими свойствами, нашедший широкое применение в различных отраслях промышленности. Особенно широко применяются монокристаллы сапфира.

Сложность изготовления деталей из монокристаллического сапфира, как уже говорилось ранее, связана с его высокой твердостью. Проявление граней на монокристаллах сапфира отмечалось неоднократно, но наиболее полно изучено огранение профилированных монокристаллических стержней сапфира, выращенных способом Степанова [3]. Изучение проводилось на качественном уровне методом фотогониографии, применявшимся ранее для монокристаллов германия и антимонида индия $[4,5,6]$. В [3] показана принципиальная возможность изучения прозрачных кристаллов этим методом и установлен ряд граней, проявляющихся на боковой поверхности кристаллов сапфира. Наиболее сильно развиты грани пинакоида $(c)$, структурного ромбоэдра $(r)$ и призмы $(a)$ и выявлено характерное соотношение их ширины как $h_{c}: h_{r}: h_{a}=8: 4: 1$. Установлено также, 
что грани $c$ и $a$, как правило, имеют переходные области ступенчатого строения, тогда как у грани $r$ таких областей не наблюдается.

В настоящей работе приведены результаты систематического исследования боковой поверхности кристаллов трех наиболее важных ориентаций сапфира, позволяющие получить полное представление об огранении кристаллов сапфира, дать рекомендации по выбору оптимальных направлений выращивания и расширить представления о проявлении АСПЭ сапфира в условиях выращивания профилированных кристаллов.

\section{Исследование боковой поверхности цилиндрических кристаллов сапфира методом видеогониографии}

Видеогониограф - оптический прибор с цифровой регистрацией, предназначенный для изучения морфологии боковой поверхности профилированных кристаллов на количественном уровне. Прототипом для него послужил разработанный ранее фотогониограф [3]. Схематическое изображение действующего лабораторного макета видеогониографа, разработанного в лаборатории Физики профилированных кристаллов ФТИ им. А.Ф. Иоффе, приведено на рис. 1. Видеогониограф выставляется в горизонте при помощи пузырькового уровня 1. Параллельный пучок света 2 выходит из осветителя 3, падает на вращающийся при помощи электродвигателя 4 кристалл 5. Скорость вращения кристалла регулируется редуктором 6. Отражения регистрируются цифровой видеокамерой 7. Математическая обработка полученного видеосигнала позволяет построить полную видеограмму, т.е. непрерывную развертку изображения боковой поверхности кристалла.

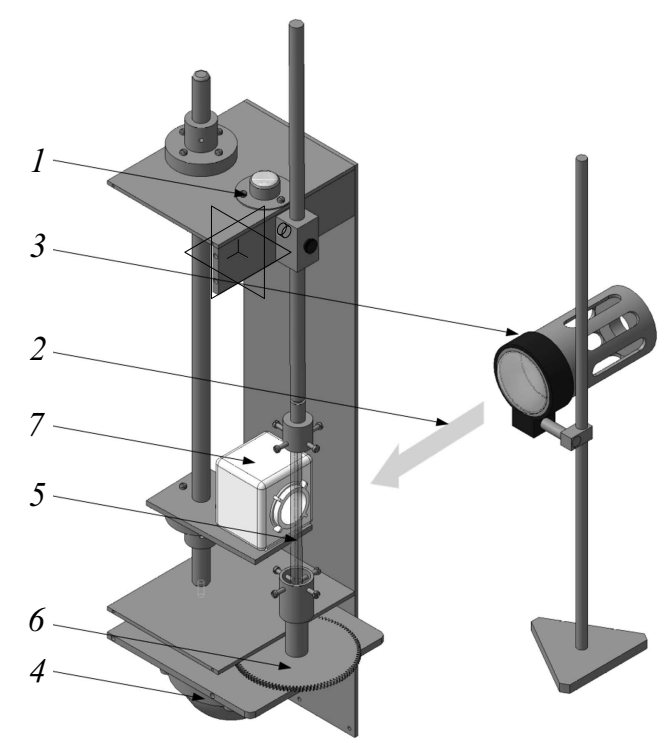

Pис. 1. Схематическое изображение конструкции действующего лабораторного макета видеогониографа.

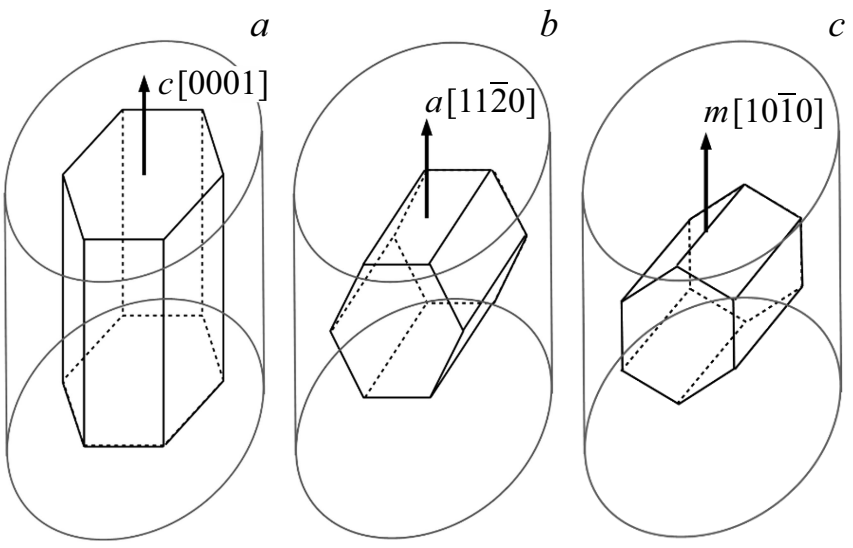

Рис. 2. Пиктограммы ориентаций кристаллов сапфира, выращенных для исследования морфологии боковой поверхности: $a$ - ориентация $c$ [0001]; $b$ - ориентация $a$ [112̄20]; $c$ - ориентация $m[10 \overline{1}]$.

Величина сигнала, усредненного по высоте видеограммы в каждом вертикальном столбике пикселей, является количественной характеристикой интенсивности отражения под заданным углом. Интенсивность отраженного сигнала зависит как от отражающей способности поверхности, так и от ее кривизны, причем наибольший уровень сигнала будет иметь место при отражении от плоских зеркальных граней. Угловая зависимость интенсивности содержит полную информацию о морфологии боковой поверхности в пределах высоты видеограммы.

Видеокамера, фиксирующая отраженный от боковой поверхности монокристалла сигнал, установлена на столике, имеющем возможность перемещаться по вертикали. Такое решение дает возможность изучать изменение морфологии боковой поверхности монокристалла по его длине и отслеживать влияние изменений условий выращивания.

Напомним, что сапфир относится к гексагональному подклассу тригонального класса симметрии, в котором возможны следующие простые формы: пинакоид $c\{0001\}$ перпендикулярный оптической оси, гексагональные призмы $a\{11 \overline{2} 0\}$ и $m\{10 \overline{1} 0\}$, группа дигексагональных призм $\{h k i 0\}$, группа ромбоэдров $\{h 0 \bar{h} l\}$, группа гексагональных дипирамид $\{h h \overline{2 h} l\}$. Для того чтобы изучить проявление всех перечисленных простых форм на боковой поверхности цилиндрических кристаллов, необходимо исследовать кристаллы как минимум трех направлений выращивания $c$ [0001], $a$ [11 $\overline{2} 0]$ и $m[10 \overline{1} 0]$ (рис. 2 ).

Монокристаллы сапфира этих ориентаций были выращены способом Степанова в виде стрежней диаметром $8 \mathrm{~mm}$. Лазерная ориентация затравочного кристалла в ростовой камере позволила выдержать заданное направление выращивания с точностью $\sim 3-5^{\prime}$. Кристаллы выращивались в стандартной осесимметричной тепловой зоне с цилиндрическим графитовым нагревателем со скоростью $0.5-1.2 \mathrm{~mm} / \mathrm{min}$ в атмосфере аргона с мак- 
Таблица 1. Простые формы, выявленные на боковой поверхности цилиндрических монокристаллов сапфира ориентации $a$ методом видеогониографии

\begin{tabular}{c|c|c|c|c|c|c|c|c|c|c}
\hline Обозначение & $c$ & - & - & - & - & $q$ & $R$ & - & - & - \\
\hline$\phi_{c}{ }^{\circ}$ & 0 & 12.6 & 16 & 21.6 & 29.4 & 32.2 & 38.2 & 42 & 44.6 & 49.8 \\
Обозначение & - & - & $r$ & - & $S$ & $\alpha$ & $t$ & - & $m$ & $D$ \\
$\phi_{c},{ }^{\circ}$ & 51.6 & 57 & 57.6 & 68.4 & 72.4 & 75.8 & 81 & 87.2 & 90 & 95.6 \\
Обозначение & $p$ & - & $S$ & $r$ & - & - & - & $R$ & - & - \\
$\phi_{c},{ }^{\circ}$ & 97.2 & 103 & 107.6 & 122.4 & 128.4 & 130.2 & 131.6 & 141.8 & 155.8 & 162.4 \\
Обозначение & - & & & & & & & & &
\end{tabular}
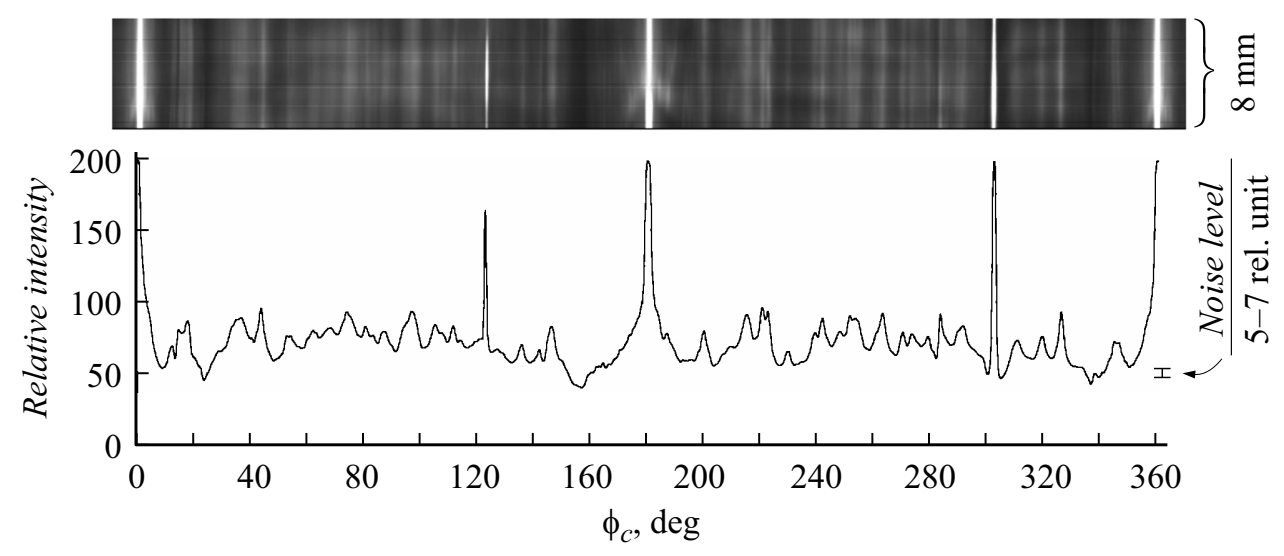

Рис. 3. Видеограмма и ее график относительной интенсивности отражения для кристалла сапфира ориентации $a$.

симально возможной выдержкой постоянства условий роста.

Рассмотрим далее результаты изучения морфологии боковой поверхности монокристаллических стержней сапфира различной ориентации, выращенных способом Степанова.

\section{Ориентация $\boldsymbol{a}[\mathbf{1 1 2} 0]$}

На рис. 3 приведена видеограмма участка боковой поверхности цилиндрического монокристалла сапфира ориентации $a$ высотой $8 \mathrm{~mm}$ и построенный по ней график относительной интенсивности отражения. На графике по оси ординат отложено значение интенсивности отражения от боковой поверхности в относительных единицах, по оси абсцисс дан угол $\phi_{c}$, откладываемый в данном случае от грани пинакоида $c\{0001\}$ (одна из граней, используемая нами в роли реперной). На графике также отмечен уровень шума (5-7 единиц относительной интенсивности отражения). Хорошо видно, что уровень шума в сравнении с интенсивностью пиков на графике незначителен, поэтому фактически все пики являются значимыми и отражают особенности морфологии боковой поверхности цилиндрических монокристаллов сапфира.

Благодаря тому, что метод видеогониографии является количественным методом и позволяет получить гра- фик относительной интенсивности отражения, появляется возможность не только сравнить морфологию кристаллов различной ориентации, но и детально изучить эволюцию морфологии поверхности одного кристалла в процессе роста (по высоте). Такое изучение дает возможность оценить стабильность ростового процесса и сделать выводы о том, насколько стабильно кристалл данной ориентации держит заданный профиль. На рис. 4 приведены графики относительной интенсивности отражения для нескольких уровней по длине кристалла сапфира ориентации $a$. На графиках также отмечены грани, имеющие общепринятые буквенные обозначения.

Графики, приведенные на рис. 4, хорошо иллюстрируют, что морфология боковой поверхности цилиндрического монокристалла сапфира ориентации $а$ весьма стабильна по высоте. На всех трех графиках прослеживаются максимумы, соответствующие одним и тем же граням, а их высота меняется незначительно (в пределах значений уровня шума).

Рис. 3 и 4 хорошо иллюстрируют, что наиболее ярко выраженными являются зеркальные грани пинакоида $c$ и ромбоэдра $r$, что согласуется с визуальными наблюдениями.

Необходимо отметить, что соотношение размеров граней $c$ к $r$ на кристалле (измеренное под микроскопом) $2: 1-2.5: 1$ совпадает с отношением ширины рефлексов на видеограмме (белых полос) и с отношением ширины 


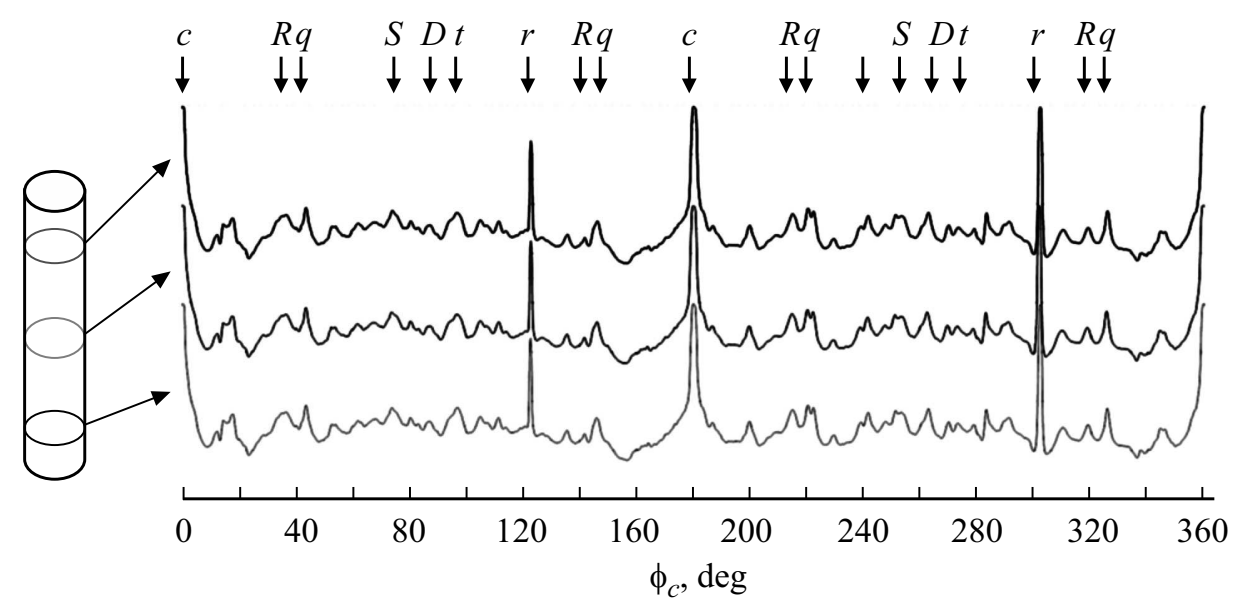

Рис. 4. Сравнение особенностей морфологии боковой поверхности цилиндрического монокристалла сапфира ориентации $a$ на нескольких уровнях по длине кристалла.

пиков этих граней на графике интенсивности (на уровне полувысоты пика). Данное наблюдение совпадает также с соотношением, установленным ранее в работе [3].

Форма пиков $c$ и $r$ различна, что связано с морфологией этих граней. Микроскопическое наблюдение показывает, что в случае грани $c$ переход к округлой поверхности происходит плавно путем сгущения ступеней, что проявляется на графике интенсивности в виде пьедестала у основания пика. У грани $r$ такого пьедестала не наблюдается, но и на кристалле переход от плоской грани к округлой части происходит резко с четким ребром между гранной и округлой поверхностями.

На боковой поверхности монокристаллов сапфира данной ориентации методом видеогониографии выявлено большое количество второстепенных граней ромбоэдров, намного превышающее количество граней, выявляемых методом фотогониографии. Полный перечень граней, выявленных нами в ходе видеогониографического изучения морфологии боковой поверхности монокристаллических стержней сапфира ориентации $a$, приведен в табл. 1.

На кристаллах ориентации $а$ выявлена 31 грань, из них 20 ранее не описывалось в огранении боковой поверхности цилиндрических монокристаллов сапфира.

Из графиков рис. 3 и 4 видно, что интенсивность двух пиков одной простой формы $r$ различна, что свидетельствует о наличии небольшой остаточной разориентации кристалла. Об этом свидетельствует также проявление некоторых параллельных плоскостей как в виде граней, так и в виде ребер (темные полосы на видеограмме и минимумы в графике интенсивности). Такое поведение второстепенных граней отмечалось и ранее на фотограммах [3].

\section{Ориентация $c[0001]$}

На рис. 5 приведена видеограмма и график относительной интенсивности отражения от боковой поверх- ности цилиндрического монокристалла сапфира ориентации $c$. Так же как и для кристаллов ориентации $a$, все пики на графике интенсивности превосходят уровень шума и являются значимыми.

Был также проведен анализ особенностей морфологии боковой поверхности на нескольких уровнях по длине кристалла. Данные приведены на рис. 6, где также отмечены грани, имеющие общеупотребительные символы.

Графики, приведенные на рис. 6, хорошо иллюстрируют, что морфология боковой поверхности цилиндрических монокристаллов ориентации $c$ меняется гораздо значительнее, чем морфология боковой поверхности кристаллов ориентации $a$. Пики от второстепенных граней имеют существенно различный уровень, а иногда и различную форму. Это, скорее всего, свидетельствует о том, что морфология боковой поверхности кристаллов ориентации $c$ более склонна реагировать на незначительные изменения в параметрах роста. Можно сказать, что кристаллы ориентации $c$ хуже держат сечение, задаваемое формообразователем, чем кристаллы ориентации $a$.

Рис. 5 и 6 хорошо иллюстрируют, что наиболее ярко выраженной на кристаллах ориентации $c$ является грань гексагональной призмы $a$. У этих граней, так же как и у грани $c$ (рис. 3), наблюдается плавный переход от грани к окружности, наблюдаемый визуально как сгущение ступеней и проявляющийся на графике интенсивности в виде пьедестала у основания пика.

На месте, где должны находиться отражения от граней гексагональной призмы $m$ (через одну позицию положения $m$, значения $\phi_{a}$ на графике (рис. 5) 30,150 и $270^{\circ}$ ), наблюдаются высокие подъемы с достаточно пологими крыльями и провалом на вершине. Это говорит о том, что грани гексагональной призмы $m$ осложнены наклонными гранями ромбоэдра, выходившими во время роста на фронт кристаллизации и проявившимися на боковой поверхности. Такое проявление наклонных граней было ранее хорошо изучено на монокристаллах германия $[4,5]$ 


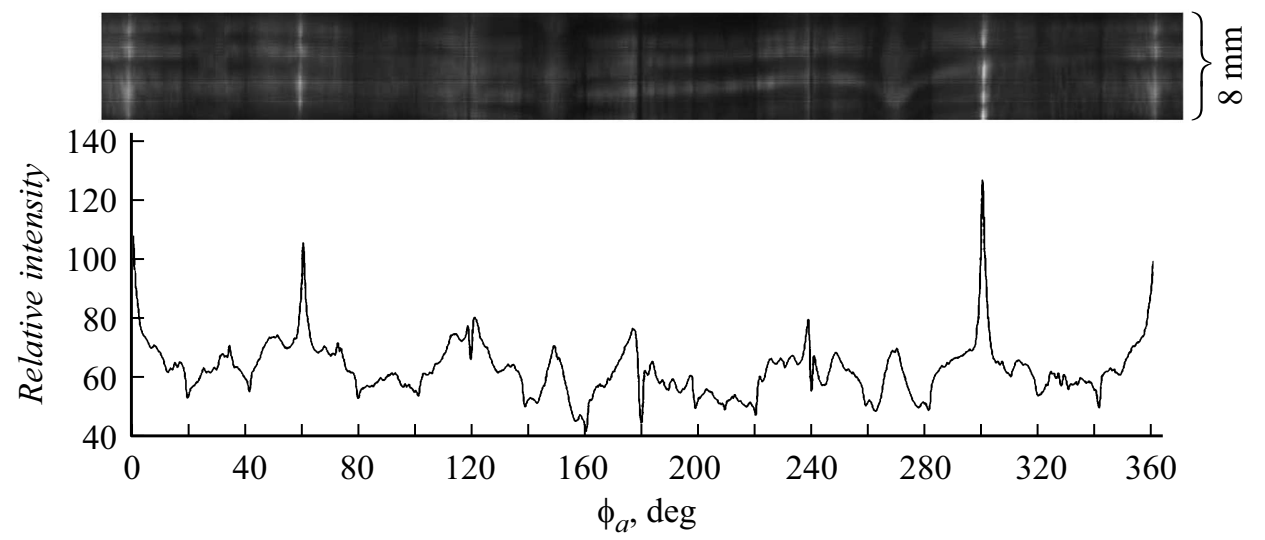

Рис. 5. Видеограмма и ее график относительной интенсивности отражения для одного из сечений боковой поверхности кристалла сапфира ориентации $c$.

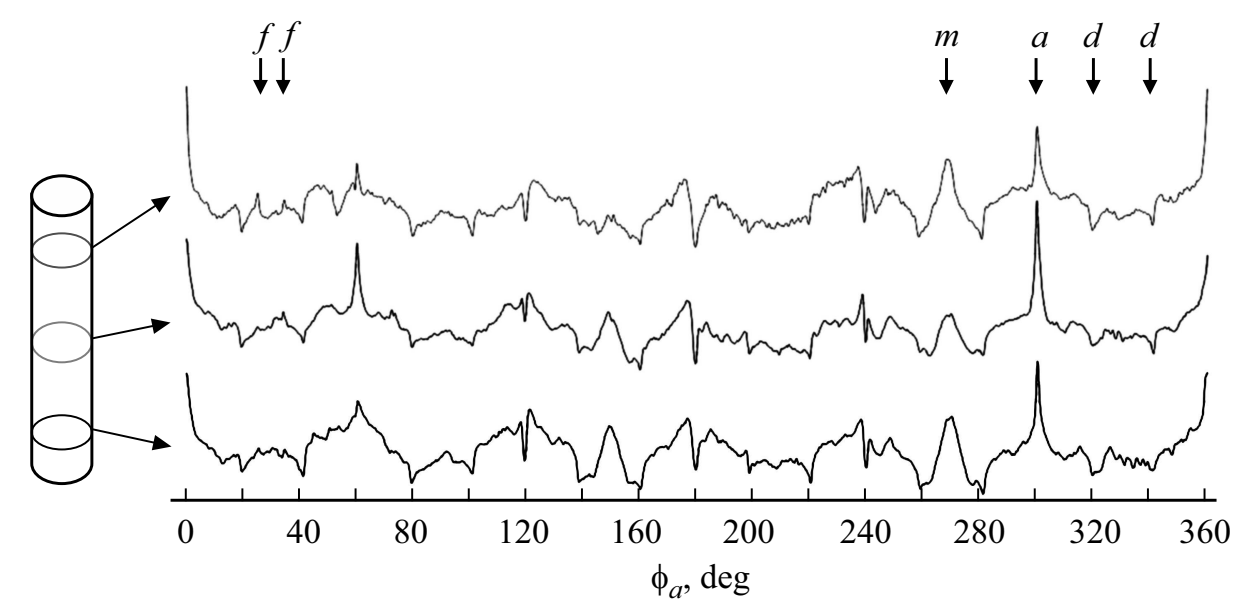

Рис. 6. Сравнение особенностей морфологии боковой поверхности цилиндрического монокристалла сапфира ориентации $c$ на нескольких уровнях по длине кристалла.

Таблица 2. Простые формы, выявленные на боковой поверхности цилиндрических монокристаллов сапфира ориентации $c$ методом видеогониографии

\begin{tabular}{c|c|c|c|c|c|c}
\hline Обозначение & $a$ & - & $d$ & - & $f$ & $m$ \\
\hline$\phi_{c},{ }^{\circ}$ & 0 & 6.6 & 19.2 & 21.8 & 23.4 & 30
\end{tabular}

и отмечалось и для сапфира [3]. Из анализа приведенных графиков можно сделать вывод, что сама грань $m$ при этом вырождается в ребро, т.е. становится очень узкой (участком с бесконечно малым радиусом кривизны) и ей соответствует лишь небольшой провал графика отражения на фоне общего подъема.

На боковой поверхности монокристаллов сапфира ориентации $c$ методом видеогониографии выявлено большое количество дигексагональных призм. Как правило, эти второстепенные грани проявляются на графике относительной интенсивности в виде небольших пиков или провалов, слабо отличающихся от уровня шума, что затрудняет их диагностику. Полный перечень граней, выявленных в ходе видеогониографического изучения морфологии боковой поверхности монокристаллических стержней сапфира ориентации $c$, приведен в табл. 2.

На кристаллах ориентации $c$ выявлено 6 граней, из них 3 ранее не описывались на боковой поверхности монокристаллических стержней сапфира. В виде зеркальной грани на кристаллах этой ориентации проявляется только грань гексагональной призмы $a$.

\section{Ориентация $m[10 \overline{1} 0]$}

На рис. 7 приведены видеограмма и график относительной интенсивности отражения от боковой поверхности цилиндрического монокристалла сапфира ориентации $m$. Аналогично таким же графикам для кристаллов ориентаций $a$ и $c$, все пики являются значимыми. Но в отличие от предыдущих случаев, морфология боковой поверхности кристаллов ориентации $m$ очень сильно реагирует даже на незначительные изменения в условиях выращивания, что хорошо иллюстрирует рис. 8. 

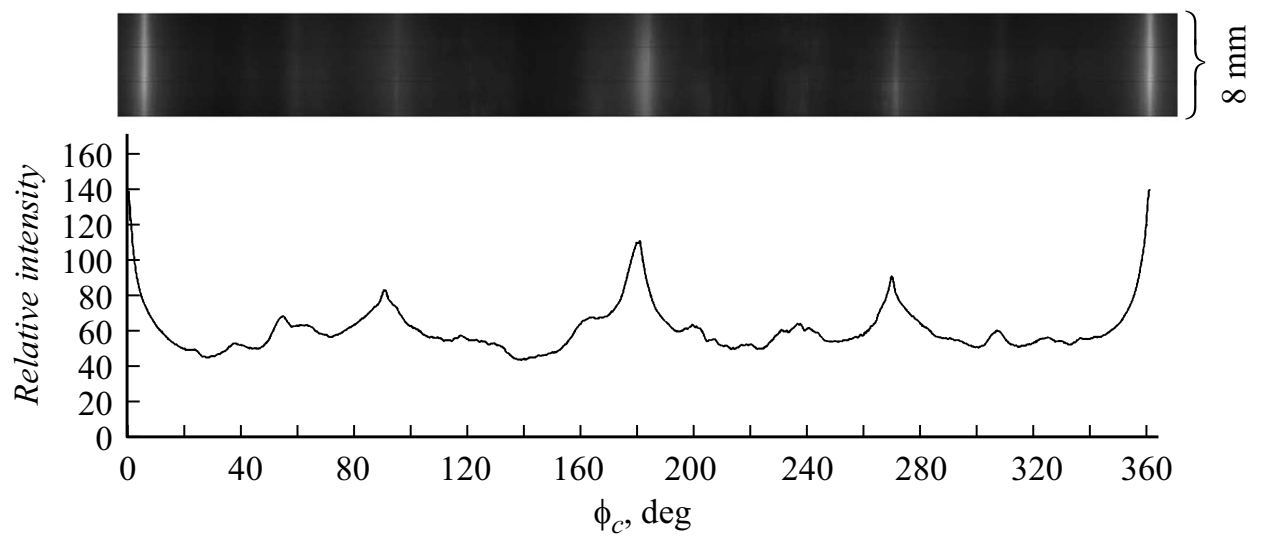

Рис. 7. Видеограмма и ее график относительной интенсивности отражения для одного из сечений боковой поверхности кристалла сапфира ориентации $m$.

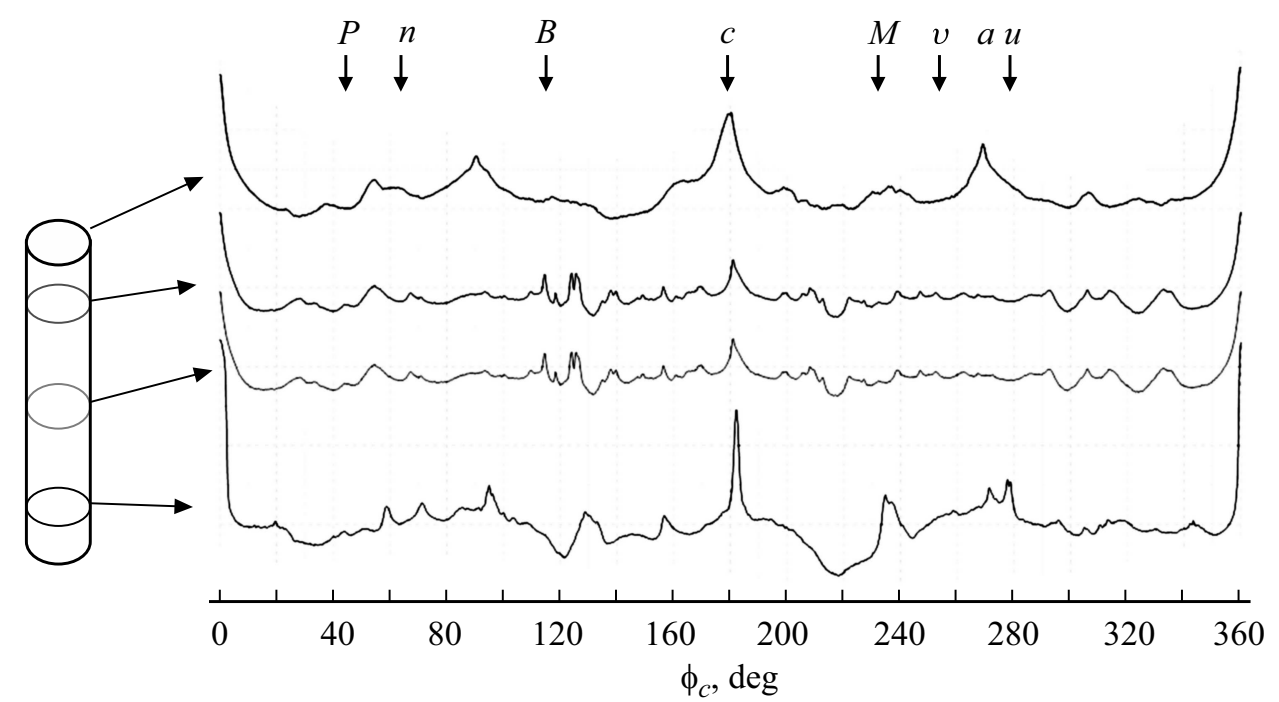

Рис. 8. Сравнение особенностей морфологии боковой поверхности цилиндрического монокристалла сапфира ориентации $m$ на нескольких уровнях по длине кристалла.

Рис. 7 и 8 хорошо иллюстрируют, что наиболее ярко выраженными на кристаллах ориентации $m$ являются грани гексагональной призмы $a$ и пинакоида $c$, но при этом только грань $c$ наблюдается на боковой поверхности всех исследованных кристаллов этой ориентации и во всех сечениях по их высоте. Грань гексагональной призмы $a$ имеет непостоянную ширину по длине кристалла и часто не различима невооруженным взглядом и не всегда проявляется в графиках интенсивности. У этих граней, так же как и у грани $c$, на кристалле ориентации $a$ (рис. 3) наблюдается плавный переход от грани к окружности, видимо также путем сгущения ступеней, что проявляется на графике в виде пьедестала у основания пика. При этом в некоторых сечениях удается выявить только пьедестал, а рефлекс от самой грани трудно различим.

На боковой поверхности монокристаллов сапфира данной ориентации методом видеогониографии выявлено большое количество гексагональных дипирамид. Но в отличие от ориентаций $a$ и $c$, где все выявленные грани в той или иной степени наблюдаются в одном сечении, на боковой поверхности кристаллов ориентации $m$ для составления полного списка проявляющихся граней необходимо было снять большое количество видеограмм на разных уровнях по высоте кристалла. Например, для кристалла, приведенного на рис. 7 и 8, для выявления всех возможных граней необходимо было снять видеограммы на 12 уровнях. При этом грани гексагональных дипирамид проявляются в виде небольших пиков или провалов графика интенсивности, слабо отличающихся от уровня шума, что затрудняет их диагностику. Полный перечень граней, выявленных нами в ходе видеогониографического изучения морфологии боковой поверхности монокристаллических стержней сапфира ориентации $m$, приведен в табл. 3 .

На кристаллах ориентации $m$ выявлено 17 граней, из них 11 ранее не описывались на боковой поверхности монокристаллических стержней сапфира. На кристаллах 


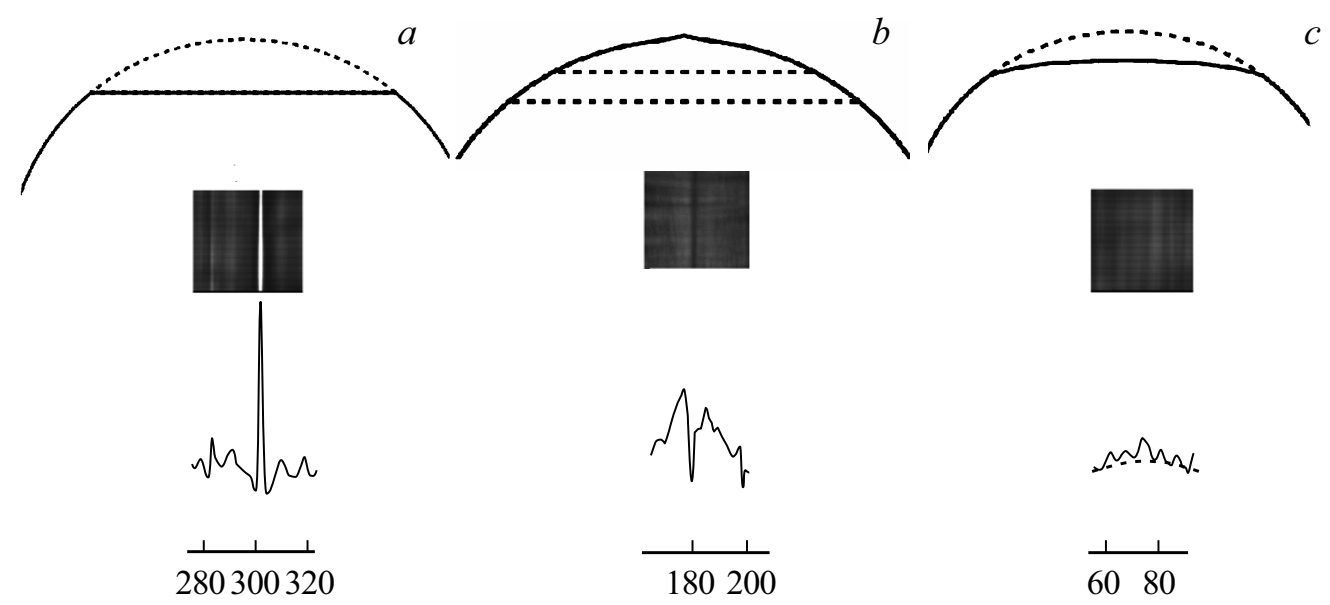

Рис. 9. Морфологические единицы боковой поверхности монокристаллических стержней сапфира, выращенных способом Степанова: $a-$ зеркальная грань; $b-$ ребро; $c-$ уплощение.

Таблица 3. Простые формы, выявленные на боковой поверхности цилиндрических монокристаллов сапфира ориентации $m$ методом видеогониографии

\begin{tabular}{c|c|c|c|c|c|c|c|c|c}
\hline Обозначение & $c$ & - & - & - & - & - & - & $P$ & $M$ \\
\hline$\phi_{c},{ }^{\circ}$ & 0 & 12.8 & 14.6 & 20 & 24.4 & 31.2 & 34.4 & 42.4 & 53.8 \\
Обозначение & - & $n$ & $B$ & - & $w$ & $v$ & $u$ & $a$ & \\
$\phi_{c},{ }^{\circ}$ & 58.6 & 61.2 & 65.4 & 67.6 & 69.8 & 74.6 & 79.6 & 90 &
\end{tabular}

данной ориентации в виде зеркальных граней проявляются грани пинакоида $c$ и гексагональной призмы $a$. Coотношение размеров $c: a$ определить достаточно сложно из-за нестабильности морфологии боковой поверхности монокристаллических стержней сапфира ориентации $m$, но примерно оно равно $8: 1$, что соответствует ранее установленной закономерности [3].

\section{Заключение}

В ходе видеогониографического исследования цилиндрических монокристаллов сапфира, выращенных способом Степанова, удалось детально изучить морфологию боковой поверхности кристаллов сапфира трех ориентаций (направлений выращивания). В результате было установлено, что на кристаллах ориентации $a$ [11 20$]$ проявляется 31 грань, на кристаллах ориентации $c$ [0001] проявляется 6 граней, на кристаллах ориентации $m[10 \overline{1} 0]$ проявляется 17 граней. Было установлено три вида морфологических единиц боковой поверхности кристаллов сапфира (рис. 9), которые по сути являются отклонениями от заданного формообразователем профиля:

1. Зеркальная грань будет проявляться на графике интенсивности в виде высокого узкого пика. При большой ширине этот пик имеет закругленную вершину. В случае кристаллов сапфира в силу их кристаллографии все плоские грани попарно параллельны. Если кристалл рос без нарушения ориентации, то интенсивность пиков от параллельных плоских граней должна быть одинаковой, в ином случае интенсивность может отличаться, причем большую интенсивность будет давать та грань, которая была наклонена к расплаву. Это хорошо видно на кристаллах ориентации $a$ и $c$ по разным значениям интенсивностей граней (рис. 3 и 5). Более детальное изучение этого явления в дальнейшем позволит использовать видеогониограф как прибор для экспрессного определения разориентации кристалла.

2. Ребро проявляется на видеограмме в виде темной полосы, а на графике интенсивности - в виде узких провалов, так как ребро - это участок с бесконечно малым радиусом кривизны. Ребра на наших кристаллах могут возникать в случае отклонения ориентации направления выращивания кристалла, когда грань рационального направления несколько наклонена в сторону от расплава. В этом случае она выклинивается. Наиболее явно ребра видны на рис. 5, где им соответствуют рефлексы, находящиеся на отметках $60,120,180$ и $240^{\circ}$ - призма $a$; $150,270^{\circ}$ - призма $m$.

3. УПлощения (участки с радиусом кривизны, большим радиуса кристалла, задаваемого формообразователем) - такие участки на графике интенсивности будут проявляться в виде невысоких подъемов, не имеющих четкого максимума, с пологими крыльями (иногда осложненными другими формами - гранями или ребрами). Характерным примером является интервал $144-156^{\circ}$ на рис. 5. В этом месте на фронте кристаллизации существовала наклонная зеркальная грань $r$, проявившаяся на боковой поверхности в виде видимой глазом ступенчатой полосы, совпадающей по положению со слабо проявляющимися гранями призмы $m$. Ширина этих подъемов $\sim 10^{\circ}$ соответствует ширине полос, наблюдаемых на кристалле.

В процессе видеогониографического исследования цилиндрических монокристаллов сапфира, выращенных 
способом Степанова, было установлено, что различные ориентации в различной степени реагируют на изменение условий роста (высоту фронта), т.е. стабильность поперечного сечения монокристаллического профиля сильно зависит от ориентации кристалла. Так, было установлено, что наиболее стабильно держат сечение (менее подвержены изменениям при изменениях условий роста) монокристаллы ориентации $a$. Наиболее подвержены изменению при изменениях условий роста кристаллы ориентации $m$.

\section{Список литературы}

[1] Степанов А.В. Получение монокристаллов определенной формы. Сб. Материалы Первого совещания по получению профилированных полупроводниковых монокристаллов способом Степанова и перспектива их применения в приборостроении. 1968. С. 4.

[2] Антонов П.И., Григорьев Н.С., Степанов А.В. // Изв. АН СССР. Сер. физ. 1971. Т. 35. Вып. 3. С. 447.

[3] Носов Ю.Г., Бахолдин С.И., Крымов В.М. // ЖТФ. 2009. Т. 79. Вып. 2. С. 76.

[4] Антонов П.И., Григорьев Н.С., Вахмянин Л.П. // Изв. АН СССР. Сер. физ. 1972. Т. 36. Вып. 3. С. 501.

[5] Антонов П.И., Бахолдин С.И., Носов Ю.Г., Калитина Е.С. // Изв. АН СССР. Сер. физ. 1983. Т. 47. Вып. 2. C. 315 .

[6] Носов Ю.Г., Антонов П.И. // Изв. АН СССР. Сер. физ. 1973. Т. 37. Вып. 11. С. 2334.

[7] Браве О. Избранные научные труды. Кристаллографические этюды. Л.: Наука, 1974. 420 с.

[8] Donnay J.D.H., Harker D. // Am. Mineral. 1937. Vol. 22. P. 446.

[9] Hartman P., Perdok W.G. // Am. Mineral. 1956. Vol. 41. P. 449.

[10] Hartman P., Perdok W.G. // Proc. Koninkl. Nederland. Akad. Wetenschap. Ser. 1952. B. 55. P. 134.

[11] Hartman P., Perdok W.G. // Acta. Cryst. 1955. N 8. P. 49.

[12] Hartman P., Perdok W.G. // Acta. Cryst. 1955. N 8. P. 521.

[13] Hartman P., Perdok W.G. // Acta. Cryst. 1955. N 8. P. 525.

[14] Hartman P. // Phys. Chem. Of the Organic Sol. Stat. 1963. Vol. 1. P. 369

[15] Watson G.W., Kelsey E.T., de Leeuw N.H., Harris D.J., Parker S.C. // J. Chem. Soc. Faraday Trans. 1996. Vol. 92. P. 433.

[16] Любалин М.Д. Рост кристаллов в расплаве. Кристаллографический анализ и эксперимент. СПб.: Наука, 2008. 390 с.

[17] Любалин М.Д. // Изв. АН СССР. Сер. физ. 1988. Т. 52. Вып. 10. С. 1970.

[18] Tasker P.W. // Am. Ceram. Soc. 1984. Vol. 10. P. 176.

[19] Mackrodt W.C., Davey R.J., Black S.N., Docherty R. // J. Crysr. Growth. 1987. Vol. 80. N 2. P. 441.

[20] Causa M., Dovesi R., Pisani C., Roetti C. // Surf. Sci. 1989. Vol. $215 \mathrm{~N}$ 1-2. P. 259.

[21] Ellis D.E., Guo J., Lam D.J. // J. Am. Ceram. Soc. 1994. Vol. 77. N 2. P. 398.

[22] Manassidis I., Gillan M.J. // J. Am. Ceram. Soc. 1994. Vol. 77. N 2. P. 335.

[23] Gay D.H., Rohl A.L. // J. Chem. Soc. Faraday Trans. 1995. Vol. 91. N 5. P. 925.
[24] Blonski S., Garofalini S.H. // Surf. Sci. 1993. Vol. 295. N 1-2. P. 263.

[25] Suzuki H., Matsubara H., Kishino J., Kondoh T. // J. Ceram. Soc. Jpn. 1998. Vol. 106. N 12. P. 1215.

[26] Marmier A., Parker S.C. // Phys. Rev. B. 2004. Vol. 69. P. 115409.

[27] Kitayama M., Glaeser A.M. // J. Am. Ceram. Soc. 2002. Vol. 85. N 3. P. 611. 